\title{
Resposta ovariana de cabras submetidas a implantes de progesterona seguidos de aplicações de gonadotrofina coriônica equina ${ }^{1}$
}

\author{
Luis Fernando Uribe-Velásquez², Maria Inês Lenz Souza ${ }^{3}$, Jose Henry Osorio ${ }^{4}$
}

\author{
1 Projeto financiado pela FAPESP - São Paulo - Brasil e pela VIP - Universidad de Caldas - Colombia - Convocatoria/2006. \\ 2 Departamento de Saúde Animal, Universidade de Caldas, Manizales, Colômbia. \\ ${ }^{3}$ Departamento de Morfofisiologia, Universidade Federal de Mato Grosso do Sul, UFMS, Campo Grande, Mato Grosso do Sul, MS, Brasil. \\ ${ }^{4}$ Departamento de Ciências Básicas, Universidade de Caldas, Manizales, Colômbia.
}

RESUMO - Objetivou-se comparar os efeitos de diferentes doses de gonadotrofina coriônica equina (eCG) na dinâmica folicular e nas concentrações hormonais em cabras alpinas. Durante a estação reprodutiva, as cabras foram submetidas à sincronização do estro e da ovulação com um dispositivo de progesterona por 14 dias. As cabras (n=24) foram divididas aleatoriamente, em quatro grupos de seis e, no dia da remoção do dispositivo, receberam 0 (controle), 200, 300 e 400 UI de eCG. O desenvolvimento folicular foi observado via ultrassonografia um dia antes da administração da eCG até a ovulação seguinte. Determinaram-se diariamente as concentrações plasmáticas de estradiol e progesterona por radioimunoensaio. Todos os animais tratados manifestaram estro. Observaram-se ciclos estrais com três e quatro ondas de crescimento folicular. O tamanho do maior folículo nos animais controle na terceira onda $(5,5 \pm 0,50 \mathrm{~mm})$ foi menor que naqueles tratados com 300 UI de eCG $(7,17 \pm 0,35 \mathrm{~mm})$. A aplicação de gonadotrofina aumentou o número de folículos pequenos e médios em relação ao grupo controle, uma vez que o número médio de corpos lúteos foi maior nas fêmeas tratadas com 400 UI $(4,27 \pm 0,23)$ em comparação àquelas tratadas com 200 UI $(1,95 \pm 0,19)$. A concentração plasmática de progesterona e estradiol diferiu entre os grupos experimentais. A combinação de progestágenos e eCG é uma alternativa adequada para a sincronização do estro e suporta o desenvolvimento de novos protocolos de técnicas reprodutivas, como a superovulação e a transferência de embriões em cabras.

Palavras-chave: cabras, dinâmica folicular, sincronização do estro, ultrassonografia

\section{Ovarian response of goats submitted to implants of progesterone followed by administration of equine corionic gonadotrophin}

\begin{abstract}
The objective of the present study was to compare the effect of different dosages of equine chorionic gonadotrophin (eCG) on the follicular dynamics and hormonal concentrations in Alpine goats. During the breeding season, the goats were submitted to estrous and ovulation synchronization with a device containing progesterone for 14 days. Female goats $(n=24)$ were divided at random into four groups of 6 animals each. On the day of dispositive removal, the animals received 0 (Control), 200, 300 and 400 UI of eCG. Follicular development was observed by ultrasonography one day prior to administration of eCG until next ovulation. The plasma estradiol $\left(E_{2}\right)$ and progesterone $\left(\mathrm{P}_{4}\right)$ concentrations were daily determined using RIA. All treated animals showed estrous. Estrous cycle with three and four waves of follicular growth were observed. Size of the largest follicle was smaller in control group animals of the third wave $(5.5 \pm 0.50 \mathrm{~mm})$ when compared to those treated with $300 \mathrm{UI}$ of eCG $(7.17 \pm 0.35 \mathrm{~mm})$. Gonadotrophin increased the number of small and medium follicles considering the control group because the average number of corpora lutea were higher in 400 UI ( $4.27 \pm 0.23$ ) females than those treated with 200 UI (1.95 \pm 0.19). Plasma concentrations of progesterone and stradiol showed differences among experimental groups. Combinations among progesterones and eCG is an adequate alternative for estrus synchronization and support the development of new protocols for reproduction techniques as superovulation and embryo transfer in goats.
\end{abstract}

Key Words: follicular dynamics, goats, estrous synchronization, ultrassonography

\section{Introdução}

A utilização da ultrassonografia na reprodução permite monitorar diariamente o desenvolvimento folicular ovariano durante o ciclo estral, demonstrando claro padrão do crescimento e regressão de folículos antrais em ovelhas (Liu et al., 2007) e cabras (Amorim et al., 2007).

Recebido em 17/6/2008 e aprovado em 19/5/2009.

Correspondências devem ser enviadas para: Ifuribe@ucaldas.edu.co 
Os métodos mais utilizados para a sincronização do estro e da ovulação em pequenos ruminantes envolvem progesterona e/ou progestágenos e a administração intramuscular de eCG (Martínez et al., 2007; Uribe-Velásquez et al., 2008a). A gonadotrofina coriônica equina (eCG) é produzida pelo endométrio das fêmeas equinas entre os dias 40 e 130 da gestação; apresenta atividade semelhante à do hormônio folículo estimulante (80\%), mas também alguma atividade de hormônio luteizante (20\%) (Barret et al., 2004). Doses baixas de eCG (350-500 UI) são comumente usadas em ovelhas cíclicas após o tratamento com progestágenos visando sincronizar e diminuir o intervalo estro-ovulação (Cline et al., 2001). Tratamentos com doses baixas de eCG limitam a taxa de ovulação (Barret et al., 2004) e a fertilidade (Ali, 2007) em ovelhas. O tratamento com 500 UI de eCG pode alterar o número de folículos antrais, a capacidade esteroidogênica e o crescimento folicular (Barret et al., 2004). Tratamentos em ovelhas Suffolk com 1000 UI de eCG resultam em porcentagem semelhante de mórulas e blastocistos colhidos, em comparaçãoà administração de FSH (Silveira \& Kozicki, 2001). Na ovelha, a gonadotrofina coriônica equina incrementa a taxa de ovulação pelo recrutamento dos folículos antrais pequenos e eleva sua taxa de crescimento (Driancourt \& Frick, 1992). Entretanto, não diminui os efeitos de atresia folicular (Moor et al., 1985). Folículos expostos a eCG sintetizam quantidades maiores de progesterona (Driancourt \& Frick, 1992). Da mesma forma, tem-se reportado que o uso repetitivo desta gonadotrofina coriônica de origem animal pode produzir anticorpos interespécies (Herveé et al., 2004), os quais podem interferir na resposta ovulatória de cabras (Drion et al., 2001).

Mediante o uso da ultrassonografia transretal, avaliaram-se os efeitos da sincronização do estro com progestágeno utilizando-se dispositivo de progesterona durante 14 dias e gonadotrofina coriônica equina sobre o desenvolvimento folicular e a endocrinologia reprodutiva em fêmeas caprinas alpinas durante a estação reprodutiva.

\section{Material e Métodos}

O trabalho experimental foi desenvolvido na FMVZ/ UNESP(Botucatu-São Paulo), utilizando-se 24 fêmeas caprinas adultas da raça alpina (2 a 5 anos) com peso corporal de 35 a $42 \mathrm{~kg}$ durante a estação reprodutiva. Os animais foram mantidos em boxes de $3 \times 3 \mathrm{~m}$, sob luminosidade natural. As fêmeas foram distribuídas em quatro grupos: o controle $(n=6)$ com estro natural; os grupos 2 , 3 , e $4(n=6$ por grupo) tratados com $0,3 \mathrm{~g}$ de progesterona (CIDR, AHI Plastic Moulding Company, Hamilton, New Zealand) por
14 dias. No momento da remoção do dispositivo, administraram-se 200, 300 e 400 UI de eCG (Novormon $5000^{\mathrm{R}}$, Gonadotrofina coriônica equina, Syntex, S.A., Buenos Aires, Argentina), respectivamente, nos grupos 2, 3, e 4. A partir desse momento, monitoraram-se as cabras em posição de estação por meio de ultrassom (SSD-500; Aloka Co. Ltda, Japão) com transdutor linear prostático humano de 7,5 MHz de frequência (Modelo UST-660-7,5; Aloka Co. Ltda, Japão). O dia da ovulação (dia zero) foi definido a partir do momento do desaparecimento do maior folículo (>5mm). O diâmetro, a posição e as características das estruturas ovarianas foram anotados em fichas individuais. A emergência da nova onda foi definida como sendo de um pool de pequenos folículos com diâmetro médio de 3 a 4 mm, que deram origem a um ou mais folículos com diâmetro maior ou igual a 5 mm. O dia da emergência da onda foi aquele em que o folículo apresentava $3 \mathrm{~mm}$ de diâmetro, seguido por um aumento em seu diâmetro para valores iguais ou superiores a $4 \mathrm{~mm}$ (Menchaca \& Rubianes, 2001; Rubianes et al., 2003). O diâmetro folicular foi obtido pela média da maior distância ( $\mathrm{mm}$ ) entre dois pontos da cavidade antral dos folículos. As imagens ultrassonográficas foram armazenadas em vídeo, e marcadas com diagramas da posição de todos os folículos $>2 \mathrm{~mm}$.

As fêmeas foram mantidas com um macho vasectomizado para a observação da manifestação do estro.

A alimentação consistiu de uma ração concentrada e feno de Cynodon dactylon (L) "Coast Cross” (20 versus 4,98\% de proteína bruta e 5,05 versus 35,88\% de fibra bruta, respectivamente). Os animais receberam concentrado ( $1,5 \mathrm{~kg} / \mathrm{cabeça/dia)} \mathrm{e} \mathrm{feno} \mathrm{(2,0} \mathrm{kg/cabeça/dia),} \mathrm{e} \mathrm{tiveram}$ disponibilidade ad libitum de mistura mineral e água.

Em todas as cabras, pela manhã às ( $8 \mathrm{~h})$, colheram-se amostras de sangue, por venopunção jugular, antes da retirada do dispositivo e durante todo o período experimental. As amostras de sangue foram colhidas em tubos heparinizados e, imediatamente após, foram centrifugadas a $2.500 \mathrm{rpm}$ durante 15 minutos, e o plasma obtido foi armazenado a $-20^{\circ} \mathrm{C}$, para posterior determinação hormonal por radioimunoensaio (RIE). A quantificação de progesterona foi realizada pela técnica definida por Lafrance \& Goff (1985), com algumas alterações. Assim, a extração foi trocada pelo danazol (McGinley \& Casey, 1979), e a separação do duplo anticorpo foi substituída pelo charcol. A sensibilidade do ensaio para progesterona foi de $0,1 \mathrm{ng} / \mathrm{mL}$. Todas as amostras foram analisadas num só ensaio, desenvolvido no Centro de Investigação de Reprodução Animal - CRRA, da Université de Montréal, St-Hyacinthé, Québec, Canada. A sensibilidade do ensaio para estradiol $\left(E_{2}\right)$ foi de $8 \mathrm{pg} / \mathrm{mL}$ e a dosagem feita por RIE, 
no Laboratório de Endocrinologia do Departamento de Reprodução Animal e Radiologia Veterinária da UNESPBotucatu, utilizando-se kits comerciais Coat-A-Count (DPC, Los Angeles, CA, USA) em fase sólida, e um contador gamma Vitek Count 48.

Os efeitos da eCG nas concentrações plasmáticas de progesterona e estradiol foram determinados pela análise de medidas repetidas utilizando-se o programa Statistical Analysis System (Latour \& Littell, 1996). Para os efeitos fixos (tratamento, dia, tratamento $\times$ dia), utilizou-se o teste F e, para as comparações múltiplas das médias, o teste de tukey-kramer. Para a análise da taxa de crescimento e da população folicular total, usou-se ANOVA e as médias foram comparadas pelo teste F. Os folículos foram classificados em pequenos (2-2,5 mm), médios (3-3,5 mm) e grandes $(>4 \mathrm{~mm})$. As médias da população dos folículos pequenos, médios e grandes foram transformadas (Log) antes de serem submetidas à ANOVA e comparadas pelo teste $\mathrm{F}$.

\section{Resultados e Discussão}

Todas as fêmeas caprinas dos grupos experimentais manifestaram estro nas 72 horas seguintes ao final da sincronização e não apresentam diferença $(P>0,05)$, corroborando os intervalos achados por Kridli \& AlKhetib (2006) e Barrett et al. (2004), que, trabalhando com 600 e 500 UI de gonadotrofina coriônica equina, mostraram valores em 24-72 horas. Doses de 1.250 UI do mesmo hormônio foram utilizadas por Riesenberg et al. (2001) em cabras fora da estação reprodutiva, que observaram o mesmo tempo de intervalo. No trabalho de Fonseca et al. (2008), utilizando 200 UI de gonadotrofina coriônica equina e administrando prostaglandina $\mathrm{F}_{2}$ á no momento de retirada da esponja (dia nove) em cabras Alpinas, observou-se redução do intervalo ao estro, que em $88 \%$ dos animais, ocorreu nas primeiras 36 horas.

Segundo Freitas \& Salles (2000), a aplicação de 200 UI de gonadotrofina coriônica equina em cabras Saanen sincronizadas com progestágenos, modificou o periodo do intervalo entre a remoção do dispositivo e o início do estro (22,6 \pm 10,1 versus 26,6 \pm 10,6 h). Os tratamentos hormonais com progestágenos associados ao gonadotrofina coriônica equina têm apresentado bons resultados de respostas de estro, uma vez que essa gonadotrofina atua no recrutamento folicular ovariano de fêmeas cíclicas ou acíclicas (Mies Filho et al., 1989).

Nenhum dos fatores, como localização dos ovários, condição corporal ou peso vivo, afetou o monitoramento dos ovários. Foram identificadas quatro ondas de crescimento folicular em três animais do grupo controle. Nas fêmeas restantes, três animais controle e nos seis indivíduos que compunham os grupos 2, 3 e 4, observaramse três ondas de desenvolvimento folicular. Tenório Filho et al. (2007) observaram a apresentação de três (33,3\%) e quatro ondas $(66,6 \%)$ de desenvolvimento folicular em cabras anglo-nubianas.

O dia de emergência do folículo dominante nas três ondas de crescimento folicular (Tabela 1) não diferiu entre os experimentos $(\mathrm{P}>0,05)$, apresentando valores muito semelhantes aos reportados por Tenório Filho et al. (2007), de $1 ; 6,7$ e 14 .

O dia em que o folículo dominante atingiu seu diâmetro máximo na primeira e segunda ondas não diferiu (Tabela 1) entre os grupos. Já na terceira onda foi diferente entre os grupos experimentais $(\mathrm{P}<0,05)$.

O folículo dominante ovulatório da terceira onda nos grupos controle e nas 200 e 300 UI de gonadotrofina coriônica equina atingiu seu diâmetro máximo bem mais tarde que nos animais das 400 UI de gonadotrofina coriônica equina (Tabela 1). Os valores para o folículo dominante dos animais controle foram próximos aos mostrados por Uribe-Velásquez etal. (2002), de4,29 0,26 mm.

O diâmetro máximo atingido pelo folículo dominante na primeira onda foi maior $(\mathrm{P}<0,01)$ nas $400 \mathrm{UI}$ de gonadotrofina coriônica equina em comparação aos animais controle (Tabela 1). Evento semelhante foi observado na terceira onda, no qual o diâmetro máximo dos folículos observados com a aplicação de 300 UI de gonadotrofina coriônica equina foi superior $(\mathrm{P}<0,01)$ ao grupo controle. Para o diâmetro máximo observado no folículo dominante foram relatados valores de 8,2 $\pm 0,8 \mathrm{~mm}$ por Barrett et al. (2004), superiores aos citados nesta pesquisa. Entretanto, UribeVelásquez et al. (2002) reportaram valor de 5,36 \pm 0,26 mm utilizando também 500 UI, muito semelhante para o diâmetro máximo do folículo dominante em ovelhas.

Menchaca et al. (2007) ressaltaram que o início da resposta superovulatória na ausência de folículos grandes desencadeou maior taxa de ovulação e melhor produção de embriões em cabras Alpinas. A administração de gonadotrofina coriônica equina no momento de retirada do dispositivo, possivelmente diminuiu os efeitos negativos de progesterona na dinâmica do crescimento folicular e na ovulação (Noel et al., 1994). O crescimento do folículo dominante nos animais tratados com gonadotrofina coriônica equina foi maior que no grupo controle, concordando com os resultados de Ali (2007).

$\mathrm{O}$ aumento do diâmetro do folículo dominante nos animais recebendo gonadotrofina coriônica equina, pode ter sido provocado pelos efeitos da gonadotrofina no eixo 


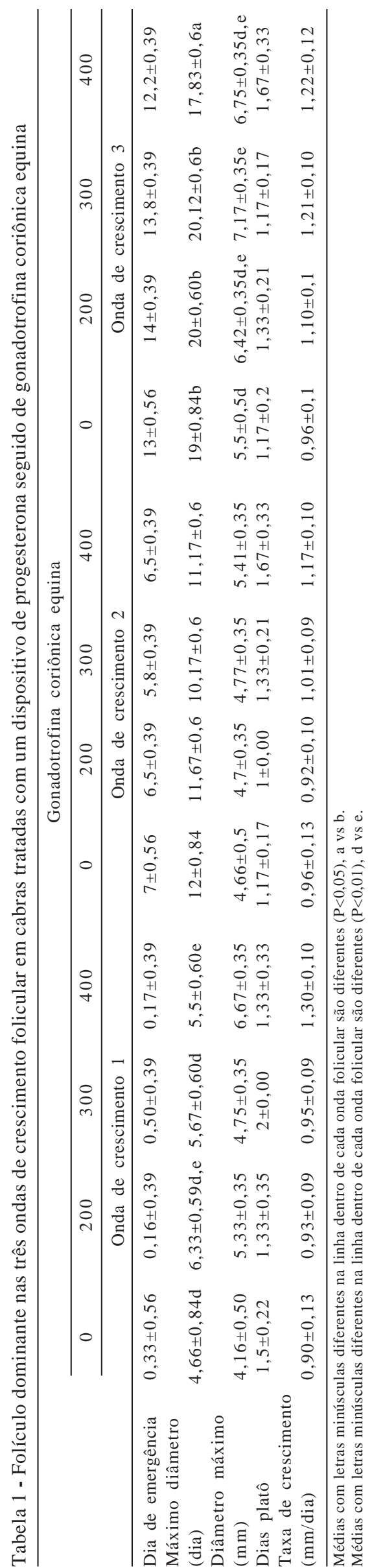

hipotálamo-hipófise-ovário e pelas alterações nos mecanismos regulatórios intraovarianos, devido, principalmente, à sua meia vida prolongada e pela sua atividade do ao LH e ao FSH. Assim, estas propriedades não somente são benéficas, como, têm seus efeitos negativos na sequência normal dos eventos fisiológicos do desenvolvimento folicular e maturação oocitária (Noel et al., 1994).

Os dias de platô não diferiram $(\mathrm{P}>0,05)$ entre os grupos experimentais, com valores médios entre 1 e 2 dias, similares aos resultados demonstrados por Rubianes et al. (1996). Valores superiores de 2,4 $\pm 0,6$ dias para esta fase tem sido relatados por Barrett et al. (2004).

Do mesmo modo, a taxa de crescimento não foi diferente $(\mathrm{P}>0,05)$ entre os grupos estudados (Tabela 1$)$. Os valores observados para a taxa de crescimento estão de acordo com os resultados obtidos no trabalho de Castonguay et al. (1990; 0,9 a 1,7 mm/dia) e de Ali (2007; 1,02 a 1,06 mm/dia) em ovelhas. Leyva et al. (1998) sugerem que a taxa de crescimento de alguns folículos, quando comparada a de outros que crescem mais rapidamente, pode afetar a qualidade do oócito no momento da ovulação.

Durante o início e a metade da fase luteal, observou-se diariamente crescimento dos folículos pequenos. A aplicação de gonadotrofina coriônica equina provocou aumentos $(\mathrm{P}<0,05)$ no número dos folículos pequenos na primeira e segunda onda de crescimento folicular. Na terceira onda de crescimento, não foram observadas diferenças ( $\mathrm{P}>0,05$; Tabela 2).

Estudos têm comprovado que as concentrações de progesterona afetam o tamanho folicular. Assim, folículos que crescem em períodos de alta concentração de progesterona são menores que aqueles que se desenvolvem em baixa concentração (Ginther \& Kot, 1994). Segundo Uribe-Velásquez et al. (2008b), os efeitos inibitórios da progesterona exógena na dinâmica folicular ovina são mediados pelas alterações n,a frequência dos pulsos de LH. Os mecanismos dessa inibição podem afetar os programas de sincronização do estro e da ovulação, assim como os protocolos envolvendo superovulação em pequenos ruminantes.

No estudo de Leyva et al. (1998), a administração do CIDR seguido de gonadotrofina coriônica equina (750 UI) na sua retirada em ovelhas Suffolk, gerou maior recrutamento de folículos $>2 \mathrm{~mm}$ nas 22 horas seguintes, mas essa quantidade diminuiu com o tempo, chegando a ser menor que no grupo controle nas 52 horas seguintes, possivelmente pelos efeitos endócrinos intraovarianos.

Os resultados para o número médio dos folículos pequenos foram similares aos achados de Noel et al. (1994), utilizando a técnica de laparoscopia em ovelhas Suffolk. 
Esses autores observaram que a aplicação de 800 UI de gonadotrofina coriônica equina depois da retirada da esponja intravaginal (40 mg de FGA) aumentou a população dos folículos pequenos durante a fase folicular, diminuindo logo depois na terceira onda, sem apresentar diferenças em comparação ao grupo controle. Resultados semelhantes foram ainda obtidos por Ali (2007) e Uribe-Velásquez et al. (2008a) em ovelhas, com a mesma dose de gonadotrofina coriônica equina administrada antes ou no momento da remoção do dispositivo de progesterona. Estes autores mostraram que a aplicação de gonadotrofina coriônica equina (500 UI) provocou aumento significativo dos folículos pequenos nos dias -2, -1 pré-ovulatórios e no dia 6 após ovulação, apresentando 3,43 $\pm 0,30 ; 4,29 \pm 1,06$ e 4,43 \pm 0,30 folículos, respectivamente, nos animais controle. Conforme relatos de Riesenberg et al. (2001), a população de folículos pequenos aumentou após a remoção da esponja de progesterona em cabras submetidas a aplicação de 1.200 UI da mesma gonadotrofina.

Na primeira onda de desenvolvimento folicular, os resultados comprovaram redução $(\mathrm{P}<0,05)$ no número de folículos médios do grupo controle em comparação aos grupos tratados e, da mesma forma, na segunda onda (Tabela 2). Na terceira onda de crescimento, houve leve diminuição no número de folículos médios, diferindo do grupo controle.

A aplicação da gonadotrofina provocou $(\mathrm{P}<0,05)$, maior número de folículos médios nas fases folicular e luteal do ciclo estral. O maior número de folículos médios após a ovulação pode ser atribuído ao maior pool de folículos pequenos presentes.

O número médio dos folículos grandes não diferiu entre os grupos experimentais $(\mathrm{P}>0,05)$, ainda que, durante a primeira onda folicular, os animais recebendo $300 \mathrm{e}$ 400 UI de eCG tenham apresentado número superior de folículos grandes. Noel et al. (1994) verificaram também número significativamente maior de folículos grandes em ovelhas Suffolk quando administraram respectivamente, CIDR + 750 UI de eCG ou 40 mg de FGA + 800 UI de eCG.

Entretanto, uma pesquisa desenvolvida por Castonguay et al. (1990), utilizando a técnica de laparoscopia, destacou que, possivelmente, um número significativo de folículos com diâmetro de 1-3 mm pode induzir a atresia dos folículos grandes em fêmeas ovinas.

Esses resultados indicam que, em cabras Alpinas, o crescimento dos folículos antrais maiores que $2 \mathrm{~mm}$ acontece diariamente durante o início e a metade da fase luteal do ciclo estral. Durante cada onda, folículos maiores que $2 \mathrm{~mm}$ desenvolveram-se de um pool e só alguns continuaram sua maturação e crescimento. Segundo Noel et al. (1993) e 
Ravindra et al. (1994), estes folículos atingem a ovulação ou sofrem atresia.

Houve diferença nos dias ( $\mathrm{P}<0,0001)$ e interação grupo $\times$ dia $(\mathrm{P}<0,0001)$. As fêmeas sincronizadas com o CIDR + eCG em diferentes dosagens apresentaram aumento $(\mathrm{P}<0,0001)$ das concentrações plasmáticas de progesterona em comparação aos animais controle.

Nos animais controle, as concentrações circulantes de progesterona foram baixas no dia 0 , confirmando o dia da ovulação, com aumentos nos dias 8, 10 e 12. A partir deste momento, as concentrações de progesterona começaram a diminuir gradativamente (Figura 1 ).

No primeiro dia após ovulação, as fêmeas tratadas com as $400 \mathrm{UI}$ de eCG mostraram aumento $(\mathrm{P}<0,001)$ nas concentrações plasmáticas de progesterona, diferentemente dos animais controle. Do mesmo modo, no segundo dia do ciclo estral, nos animais recebendo 400 UI de gonadotrofina coriônica equina foi observada uma concentração de progesterona superior $(\mathrm{P}<0,001)$ quando comparada com o controle. As concentrações dos animais recebendo 400 UI de gonadotrofina coriônica equina também foram diferentes $(\mathrm{P}<0,001)$ das obtidas com 300 e 200 UI de gonadotrofina coriônica equina no mesmo dia.

As concentrações de progesterona foram aumentando gradativamente após o terceiro dia do ciclo estral, mostrando-se superiores $(\mathrm{P}<0,05)$ no quarto dia, nos grupos com aplicação de 300 e 400 UI de gonadotrofina coriônica equina. Do $5^{\circ}$ até o $16^{\circ}$ dia, não foram observadas diferenças, mesmo que as fêmeas recebendo as 300 UI de gonadotrofina coriônica equina tenham apresentado concentrações plasmáticas de progesterona superiores às dos outros grupos. Aumento nas concentrações plasmáticas de progesterona também foram observados nos mesmos períodos por Kridli \& Al-Khetbi (2006) e Liu et al. (2007) em pesquisa com ovelhas cíclicas.

No dia 17 do ciclo estral, o grupo das 400 UI de eCG apresentou concentrações de progesterona maiores $(\mathrm{P}<0,001)$ que as dos grupos controle e 300 UI de eCG. Também foram evidenciados aumentos $(\mathrm{P}<0,001)$ no dia 18 , nos grupos com 400 e 300 UI de eCG, cujas concentrações foram superiores às do grupo controle (Figura 1).

No final da fase lútea (dia 19), as cabras recebendo as 300 UI de eCG apresentaram concentrações de eCG $(\mathrm{P}<0,05)$ superiores às observadas nas cabras com implante de400 UI e dos grupos controle e com 200 UI de ECG (Figura 1).

O número de corpos lúteos foi maior $(\mathrm{P}<0,05)$ nas cabras com implante de 400 UI de eCG que nas 200 UI de eCG $(4,27 \pm 0,23$ vs $1,95 \pm 0,19 \mathrm{CL} ; \mathrm{P}<0,05)$. Os animais controle e os que receberam somente 200 UI de eCG tiveram no máximo

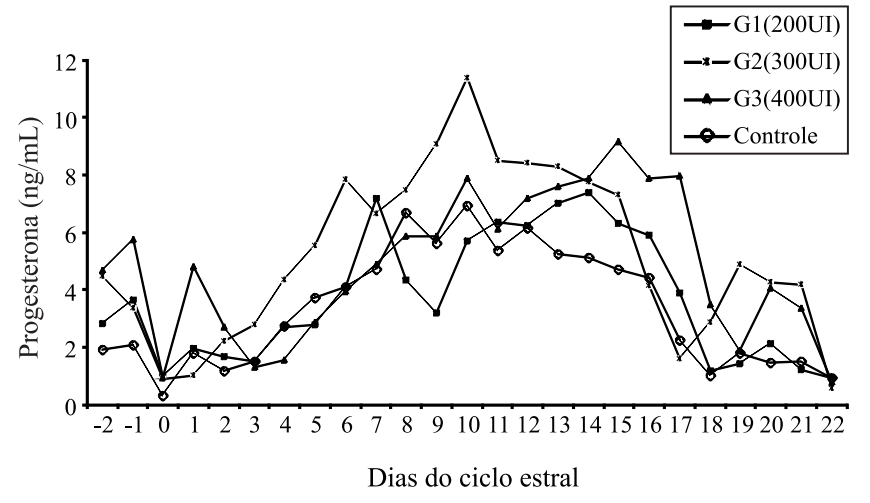

Figura 1 - Concentrações plasmáticas de progesterona em cabras tratadas com dispositivo de progesterona, seguido da aplicação de diferentes doses de gonadotrofina coriônica equina durante a estação reprodutiva.

dois corpos lúteos. Entretanto, não foi observada quantidade diferente nem significativa de corpos lúteos nas 300 e 400 UI de eCG. Esses dados corroboram os achados de Ritar et al. (1989) em cabras Cashemere. Um número menor de corpos lúteos foi achado por Liu et al. (2007) em ovelhas cíclicas com implantes 500 UI de eCG (2,3 \pm 0,6/ovelha). Entretanto, Riesenberg et al. (2001), pesquisando doses de 1.200 UI de eCG, observaram em média 3,2 \pm 1,6 CL/cabra utilizando o dispositivo de progesterona durante 12 dias. $\mathrm{O}$ aumento nas concentrações plasmáticas de progesterona nesse período pode ser resultado da atividade do corpo lúteo somado à atividade de folículos grandes luteinizados. Por tanto, o eCG provoca hiperestimulação folicular, elevando o tamanho do corpo lúteo evidenciando sua atividade luteotrófica (Evans \& Robinson, 1980; Barrett et al., 2004).

Os resultados deste estudo estão de acordo com os achados de Pearce \& Robinson (1985) em ovelhas Merino. Esses autores demonstraram a existência de aumento linear na taxa ovulatória quando aumentaram a dose de eCG (300 e 600 UI), elevando as concentrações plasmáticas de progesterona; estabeleceu-se, possivelmente, uma relação direta entre a dosagem de eCG, corpos lúteos, taxa ovulatória, e as concentrações plasmáticas de progesterona e estradiol (Evans \& Robinson, 1980). Também com ovelhas, Barrett et al. (2004) e Uribe-Velásquez et al. (2002; 2008a) notaram concentrações mais elevadas de progesterona nas fêmeas submetidas à administração de 500 UI de eCG durante a estação reprodutiva.

Aumentos nas concentrações de progesterona em resposta à administração de eCG podem aumentar a taxa de gestação em ovelhas (Nephew et al., 1994) e em fêmeas bovinas (Nishigai et al., 2001; Thatcher et al., 2002). 
Houve efeito do dia $(\mathrm{P}<0,01)$ e da interação tratamento $\times$ dia $(\mathrm{P}<0,001)$. Nas cabras do grupo controle, as concentrações plasmáticas de estradiol aumentadas no dia -2 antes da ovulação. Da mesma forma, também foram observados aumentos ( $\mathrm{P}<0,001)$ nos dias 7 e 19 (Figura 2) após ovulação. Os resultados estão próximos aos encontrados por Ravindra et al. (1994) em ovelhas.

No sétimo dia após a ovulação, as fêmeas tratadas com as maiores concentrações de eCG (300 e 400 UI de eCG) apresentaram aumento $(\mathrm{P}<0,001)$ das concentrações de estradiol em comparação à do grupo controle (Figura 2).

Do mesmo modo, no décimo dia do ciclo estral, nos animais dos grupos recebendo as 400 e 300 UI de eCG a concentração de estradiol foi superior $(\mathrm{P}<0,01)$ quando à do grupo controle.

Já no dia 19 do ciclo estral, as concentrações de estradiol nas cabras com 400 UI de eCG foram superiores $(\mathrm{P}<0,01)$ às do grupo controle, e, no mesmo dia, os grupos das 200 e 300 UI de eCG mostraram valores de estradiol superiores aos do grupo controle $(\mathrm{P}>0,05)$.

As pesquisas apontam que cada pulso de hormônio luteinizante ( $\mathrm{LH}$ ) é seguido de aumento nas secreções de estradiol e de androstenediona (Campbell et al., 1990), indicativo de que os folículos antrais ovinos são extremamente sensíveis às flutuações das concentrações plasmáticas de LH.

As médias neste estudo foram próximas às reportadas por Pearce \& Robinson (1985), que constataram que a aplicação de eCG incrementa a resposta ovariana, evidenciada pela quantidade de folículos desenvolvidos. Contraditoriamente, os valores de estradiol foram semelhantes em fêmeas ovinas em resposta a 500 UI de eCG durante a estação reprodutiva em comparação ao grupo controle.

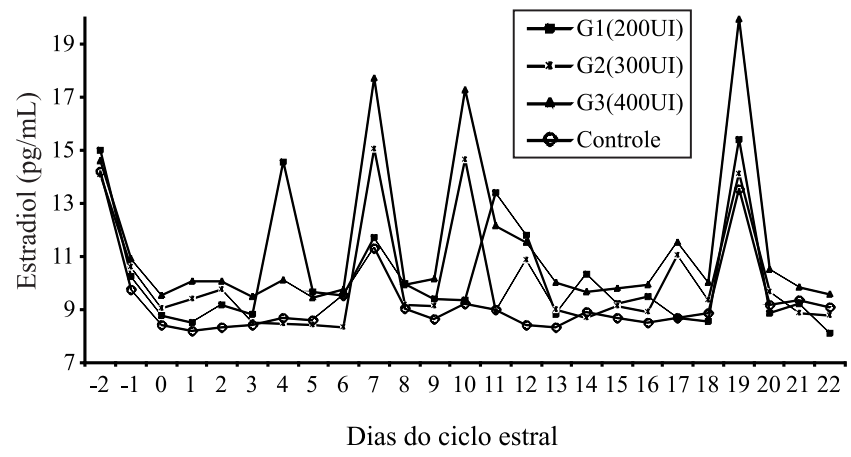

Figura 2 - Concentrações plasmáticas de estradiol (médias \pm EP) em cabras tratadas com CIDR, seguido da aplicação de diferentes doses de eCG durante a estação reprodutiva.
Kouskura et al. (1995) também evidenciaram aumentos nas concentrações plasmáticas de estradiol após a retirada do dispositivo contendo a progesterona no pró-estro e estro em ovelhas Rambouillet.

A administração de eCG em novilhas alterou a liberação de estradiol, FSH e LH no décimo dia do ciclo estral, no dia da regressão luteal e no dia posterior à regressão, enquanto que as secreções de progesterona e androstenediona não tiveram mudanças significativas. Entretanto, o aumento nas concentrações plasmáticas de estradiol foi relacionado ao desenvolvimento dos folículos ovulatórios. De acordo com Bevers et al. (1989), as fêmeas bovinas sob condições fisiológicas, a secreção pulsátil de estradiol é totalmente dependente da secreção pulsátil de $\mathrm{LH}$, e parece que o eCG, não bloqueia a secreção endógena de LH. Assim, a habilidade do progestágeno em induzir a puberdade está relacionada à maturidade do sistema neuroendócrino, o qual regula a secreção de hormônio luteinizante (Pfeifer et al., 2009).

As concentrações de estradiol aumentaram depois da regressão luteal em associação ao crescimento do folículo dominante. Também foram observados por Scaramuzzi et al. (1993) e Schrick et al. (1993) aumentos nas concentrações de estradiol no plasma nos dias 3 a 8 do ciclo.

Em ovelhas cíclicas sincronizadas com acetato de medroxyprogesterona (MAP) e 500 UI, Lui et al. (2007) observaram que as concentrações de estradiol foram superiores às obtidas no grupo controle. A intensa atividade esteroidogênica pode ser atribuída à longa meia-vida da eCG (63 horas), assim como a sua atividade de FSH e de LH.

A manipulação hormonal da função ovariana em pequenos ruminantes pode proporcionar excelente oportunidade para determinar o status folicular e, finalmente, melhorar os protocolos dos tratamentos hormonais em animais domésticos.

\section{Conclusões}

A sincronização do estro e da ovulação proposta para fêmeas caprinas é uma alternativa adequada aos métodos convencionais baseados em progestágenos, pois proporciona alto grau de sincronização do estro e da ovulação. O método tem outras vantagens, como a diminuição dos custos (tratamento e manejo dos animais), e menores efeitos nas fêmeas (redução de patologias reprodutivas e doenças relacionadas). Além disso, a ultrassonografia é um recurso eficiente para monitorar os padrões de crescimento folicular como resposta aos protocolos de superovulação. 


\section{Referências}

ALI, A. Effect of time of eCG administration on follicular response and reproductive performance of FGA-treated Ossimi ewes. Small Ruminant Research, v.72, p.33-37, 2007.

AMORIM, E.A.M.; TORRES, C.A.A.; AMORIM, L.S. et al. Dinâmica follicular em cabras da raça Toggenburg em lactação tratadas ou não com somatotropina bovina recombinante. Arquivos Brasileiros de Medicina Veterinária e Zootecnia, v.59, n.6, p.1500-1508, 2007.

BARRET, D.M.W.; BARTLEWSKI, P.M.; BATISTA-ARTEAGA, M. et al. Ultrasound and endocrine evaluation of the ovarian response to a single dose of 500 UI of eCG following a 12-day treatment with progestogen-releasing intravaginal sponges in the breeding and nonbreeding season in ewes. Theriogenology, v.61, p.311-327, 2004.

BEVERS, M.M.; DIELEMAN, S.J.; VAN TOL, H.T.M. et al. Changes in pulsatile secretion patterns of $\mathrm{LH}, \mathrm{FSH}$, progesterone, androstenedione and oestradiol in cows after superovulation with PMSG. Journal of Reproduction and Fertility, v.7, p.745-754, 1989.

CAMPBELL, B.K.; MANN, G.E.; McNEILLY, A.S. et al. Pulsatile secretion of inhibin, oestradiol and androstenedione by the ovary of the sheep during the oestrus cycle. Journal of Endocrinology, v.126, p.385-93, 1990.

CASTONGUAY, F.; DUFOUR, J.J.; MINVIELLE, F. et al. Follicular dynamics and dominance in Boorola x Finnish Landrace and Boorola x Suffolk ewes heterozygous for the F gene. Journal Reproduction and Fertility, v.89, p.193-203, 1990.

CLINE, M.A.; RALSTON, J.N.; SEALS, C. et al. Intervals from norgestomet withdrawal and injection of equine chorionic gonadotrophin or P.G. 600 to estrus and ovulation in ewes. Journal of Animal Science, v.79, p.589-594, 2001.

DRIANCOURT, M.A.; FRY, R.C. Effect of superovulation with pFSH or PMSG on growth and maturation of the ovulatory follicles in sheep. Animal Reproduction Science, v.27, p.279-292, 1992.

DRION, P.V.; FURTOOS, V.; BARIL, G. et al. Four years of induction/synchronization of estrus in dairy goats: effect on the evolution of eCG binding rate in relation with the parameters of reproduction. Reproduction, Nutrition and Development, v.41, p.401-412, 2001.

EVANS, G.; ROBINSON, T.J. The control of fertility in sheep: endocrine and ovarian responses to progestagen-PMSG treatment in the breeding season and in anoestrus. Journal of Agricultural Science, v.94, p.69-88, 1980.

FONSECA, J.F.; TORRES, C.A.A.; SANTOS, A.D.F. et al. Progesterone and behavioral features when estrous is induced in Alpine goats. Animal Reproduction Science, v.103, p.366-373, 2008.

FREITAS, V.J.F.; SALLES, M.G.F. Adaptation of eCG (equine chorionic gonadotrophin dose for estrus synchronization of dairy goats raised in Northeast Brazil: preliminary results. In: INTERNATIONAL CONFERENCE OF GOATS, 7., 2000, Tours. Proceedings... Tours: Institut de L'Élevage and INRA, 2000, p.465-466.

GINTHER, O.J.; KOT, K. Follicular dynamics during the ovulatory season in goats. Theriogenology, v.42, p.987-1001, 1994.

HERVEÉ, V.; ROY, F.; BERTIN, J. et al. Antiequine chorionic gonadotrophin (eCG) antibodies generated in goats treated with eCG for the induction of ovulation modulate the luteinizing hormone and follicle stimulating hormone bioactivities of eCG differently. Endocrinology, v.145, p.294-303, 2004.

KOUSKOURA, T.H.; KOUIMTZIS, S.; ALEXAKI, E. et al. Comparative studies of ovarian steroids in blood, and specific proteolytic enzymes in the cervical mucus, in four sheep breeds after oestrus synchronization (Progesterone and PMSG). 1. Breed variation of oestradiol-17 $b$ and progesterone in blood during natural oestrus, synchronization oestrus, and the first oestrus after synchronized oestrus. Reproduction Domestic Animal, v.30, p.8-13, 1995.

KRIDLI, R.T.; AL-KHETLIB, S.S. Reproductive responses in ewes treated with eCG or increasing doses of royal jelly. Animal Reproduction Science, v.92, p.75-85, 2006.

LAFRANCE, M.; GOFF, A.K. Effect of pregnancy on oxytocininduced release of prostaglandin F2a in heifers. Biology of Reproduction, v.3, p.1113-1119, 1985.

LATOUR, D.; LITTELL, R. Advanced general linear models with an emphasis on mixed models. Version 6.12. Cary: SAS Institute, 1996. 268p.

LEYVA, V.; BUCKRELL, B.C.; WALTON, J.S. Regulation of follicular and ovulation in ewes by exogenous progestagen. Theriogenology, v.50, p.395-416, 1998.

LIU, X.; DAI, Q.; HART, E.J. et al. Ultrasonographic characteristics of ovulatory follicles and associated endocrine changes in cyclic ewes treated with medroxyprogesterone acetate (MAP)-releasing intravaginal sponges and equine chorionic gonadotrophin (eCG). Reproduction Domestic Animal, v.42, p.393-401, 2007.

MARTÍNEZ, J.J.; IZAGUIRRE, F.; SÁNCHEZ, L. et al. Comportamiento reproductivo de ovejas Barbados Barriga Negra sincronizadas con MPA y diferentes tiempos de aplicación de eCG durante la época de baja fertilidad. Revista Científica, v.17, p.47-52, 2007.

McGINLEY, R.; CASEY, J.H. Analysis of progesterone in unextrated serum; a method using danazol (17 a-preg-4-en-20-yno $(2,3)$ isoxasol-17-ol) a bloker of steroid binding to proteins. Steroids, v.33, p.127-138, 1979.

MENCHACA, A.; RUBIANES, E. Efecto of high progesterone concentrations during the early luteal phase in the lenght of the ovulatory cycle of gotas. Animal Reproduction Science, v.68, p.69-76, 2001.

MENCHACA, A.; VILARIÑO, M.; CRISPO, M. et al. Day O Protocol: Superstimulatory treatment initiated in the absence of a large follicles improves ovarian response and embryo yield in goats. Theriogenology, v.68, p.1111-1117, 2007.

MIES FILHO, A.; ENDLER, J.O.; DUTRA, J. et al. Indução do estro ovulatório em ovelhas com o emprego de estímulos elétricos e/ou hormonais - nota prévia. Revista Brasileira de Reprodução Animal, v.13, p.229-238, 1989.

MOOR, R.M.; OSBORN, J.C.; CROSBY, I.M. Gonadotrophininduced abnormalities in sheep oocytes after superovulation. Journal Reproduction of Fertility, v.74, p.167-172, 1985.

NEPHEW, K.P.; CARDENAS, H.; McCLURE, K.E. et al. Effects of administration of human chorionic gonadotrophin or progesterone before maternal recognition of pregnancy on blastocyst development and pregnancy in sheep. Journal of Animal Science, v.47, p.283-294, 1994.

NISHIGAI, M.; TAKAMURA, A.; KAMOMAE, H. et al. The effect of human chorionic gonadotrophin on the development and function of bovine corpus luteum. Journal Reproduction Development, v.47, p.283-294, 2002.

NOEL, B.; BISTER, J.L.; PIERQUIN, B. et al. Effects of FGA and PMSG on follicular growth and LH secretion in Suffolk ewes. Theriogenology, v.41, p.719-727, 1994.

PEARCE, D.T.; ROBINSON, T.J. Plasma progesterone concentrations, ovarian and endocrinological responses and sperm transport in ewes with synchronized oestrus. Journal of Reproduction and Fertility, v.75, p.49-62, 1985.

PFEIFER, L.F.M.; CASTILHO, E.M.; ROLL, V.F.B. et al. Efeito da duração do tratamento com progestágeno e da maturidade sexual na taxa de prenhez em novilhas de corte: avaliação econômica e biológica. Revista Brasileira de Zootecnia, v.38, n.7, p.1205-1210, 2009.

RAVINDRA, J.P.; RAWLINGS, N.C.; EVANS, A.C.O. et al. Ultrasonographic study of ovarian follicular dynamics in ewes during the estrous cycle. Journal of Reproduction and Fertility, v.101, p.501-509, 1994. 
RIESENBERG, S.; MEINECKE-TILLMANN, S.; MEINECKE, B. Ultrasonic survey of follicular development following superovulation with a single application of pFSH, eCG or hMG in goats. Small Ruminant Research, v.40, p.83-93, 2001.

RITAR, A.J.; SALAMON, S.; BALL, P.D. et al. Ovulation and fertility in goats after intravaginal device-PMSG treatment. Small Ruminant Research, v.2, p.323-331, 1989.

RUBIANES, E.; CASTRO, T.; CARBAJAL, B. et al. Effect of high progesterone levels during the growing phase of the dominant follicle of wave 1 in ultrasonically monitored ewes. Canadian Journal of Animal Science, v.76, p.1-13, 1996.

RUBIANES, E.; MENCHACA, A.; CARBAJAL, B. Response of the 1-5 day-aged ovine corpus luteum to prostaglandin F2alpha. Animal Reproduction Science, v.78, p.47-55, 2003.

SCARAMUZZI, R.J.; ADAMS, N.R.; BAIRD, D.T. et al. A model for follicle selection and the determination of ovulation rate in the ewe. Reproduction Fertility Development, v.5, p.459-478, 1993.

SCHRICK, F.N.; SURFACE, R.A.; PRITCHARD, J.Y. et al. Ovarian structures during the estrous cycle and early pregnancy in ewes. Biology of Reproduction, v.49, p.1133-1140, 1993.

SILVEIRA, K.B.X.; KOZICKI, L.E. Superovulação em ovelhas Suffolk durante o anestro sazonal com FSH e PMSG. Revista
Brasileira de Reprodução Animal, v.25, n.3, p.339-341, 2001.

THATCHER, W.W.; MOREIRA, F.; PANCARCI, S.M. et al. Strategies to optimize reproductive by regulation of ovarian function. Domestic Animal Endocrinology, v.23, p.243-254, 2002.

TENÓRIO FILHO, F.; SANTOS, M.H.B.; CARRAZZONI, P.G. et al. Follicular dynamics in Anglo-Nubian goats using transrectal and transvaginal ultrasound. Small Ruminant Research, v.72, p.51-56, 2007.

URIBE-VELÁSQUEZ, L.F.; OBA, E.; LARA-HERRERA, L.C. et al. Respostas endócrinas e ovarianas associadas com o folículo dominante da primeira onda folicular em ovelhas sincronizadas com CIDR ou PGF2 $\alpha$. Revista Brasileira de Zootecnia, v.31, p.944-953, 2002.

URIBE-VELÁSQUEZ, L.F.; OBA, E.; SOUZA, M.I.L. Población follicular y concentraciones plasmáticas de progesterone (P4) en ovejas sometidas a diferentes protocolos de sincronización. Archivos de Medicina Veterinaria, v.40, p.83-88, 2008a.

URIBE-VELÁSQUEZ, L.F.; OBA, E.; SOUZA, M.I.L. Efeitos da progesterona exógena sobre o desenvolvimento folicular em ovelhas. Arquivos Brasileiros de Medicina Veterinária e Zootecnia, v.60, p.58-65, 2008b. 